\title{
Development of a new questionnaire to assess childcare providers' KAP regarding infant and young child feeding
}

\author{
Najihah Mahfuzah Zakria ${ }^{1}$, Tengku Alina Tengku Ismail ${ }^{*}$, Wan Nor Arifin Wan \\ Mansor $^{1}$, Zaharah Sulaiman ${ }^{1}$ \& Tengku Fatimatul Tengku Hassim $^{2}$
}

${ }^{1}$ School of Medical Sciences, Health Campus, Universiti Sains Malaysia, Kubang Kerian, Kelantan, Malaysia; ${ }^{2}$ Kelantan State Health Department, Wisma

Persekutuan, Kota Bharu, Kelantan, Malaysia

\begin{abstract}
Introduction: The integration of infant and young child feeding into childcare settings is important to the overall wellbeing of a community. To our knowledge, there is no questionnaire at the national context specifically on the knowledge, attitude and practice (KAP) of infant and young child feeding among childcare providers. Preexisting questionnaires are unsatisfactory due to different target populations and validation approaches. This study aims to develop a new questionnaire for assessing the KAP regarding infant and young child feeding among childcare providers in Malaysia. Methods: A new questionnaire on childcare providers' KAP was developed using literature review, expert opinions, and a theoretical framework. It was developed using a modified Delphi technique in five phases: 1. Identification of the domains, 2. Verification of the identified domains, 3. Definition of the domains, 4. Identification of relevant and representative items for each domain, and 5. Final verification of the domains and items, followed by a pre-survey evaluation. Results: The final items were verified by experts with references to relevant literatures, other questionnaires, and experts' experiences. A total of 236 items were selected after consideration of their relevancy and representativeness: 104, 90, 42 items addressing knowledge, attitude, and practice, respectively. The questionnaire was named Borang Kaji Selidik Pemakanan Bayi dan Kanak-kanak dalam kalangan Pengasuh, or IYCFCCPQ. Conclusion: The IYCF-CCPQ is a newly developed questionnaire to measure childcare providers' KAP regarding infant and young child feeding.
\end{abstract}

Keywords: KAP, infant feeding, childcare provider, questionnaire, development

\section{INTRODUCTION}

Infant and young child feeding (IYCF) includes all forms of infant feeding, including breastfeeding and complementary feeding. According to the public health recommendations issued by the World Health Organization (WHO) and the United Nations Children's Fund (UNICEF) in 2003, optimal IYCF consists of exclusive breastfeeding for the first 6 months of an infant's life, followed by the combination of breastfeeding with safe and nutritionally balanced complementary foods up to 2 years of age or beyond. These recommendations are to support the optimal growth, development, and health of children (WHO, 2003).

\footnotetext{
*Corresponding author: Tengku Alina Tengku Ismail School of Medical Sciences, Health Campus, Universiti Sains Malaysia, Kubang Kerian Kelantan, Malaysia

Tel: +609-7676621; Fax: +609-7676654; E-mail: dralina@usm.my doi: https://doi.org/10.31246/mjn-2019-0113
} 
Every woman has the right to decide how to feed her child and to receive information about the support available to her; this will help her when she reenters the workforce (Quisumbing et al., 1995; WHO, 2003; Chilton \& Rose, 2009). Nowadays, with more women in the workforce, which was reported to be about 53.6\% in 2014 (DOSM, 2014), families have become more reliant on child care services (Capizzano \& Adams, 2000; National Population and Family Development Board, 2014). Consequently, the responsibility for IYCF is shared between parents and childcare providers (Freedman \& Alvarez, 2010). Therefore, it is important to integrate the roles of parents with childcare providers to support the proper implementation of quality IYCF in childcare and daycare centres (Clark et al., 2008; Lucas et al., 2013; Asis, Al-Sadat \& Abdul Majid, 2016).

The protection, promotion, and support of IYCF are essential to public health. It is important to explore the potential of childcare providers in assisting with IYCF as a form of primary support to working mothers after they have returned to work. However, little is known about these childcare providers' knowledge, attitudes, and practices (KAP) regarding IYCF, both globally and nationally. There is also a lack of evidence about the factors affecting the KAP regarding IYCF of childcare providers in Malaysia.

In order to facilitate data collection and the answering of research questions on this topic, a questionnaire needs to be designed and properly validated (Giesen et al., 2012). In searching for valid, reliable questionnaires measuring childcare providers' KAP regarding IYCF, we found a number of questionnaires that varied significantly in their domains, theoretical backgrounds, and validation approaches. Furthermore, most pre- existing questionnaires for childcare providers were developed in the Western countries (Clark et al., 2008; Freedman \& Alvarez, 2010; Lucas et al., 2013). Given that the educational, socioeconomic, and cultural backgrounds of childcare providers in Malaysia differ significantly from those of Western countries (Clark et al., 2008; Freedman \& Alvarez, 2010; Lucas et al., 2013), hence, the adoption of these questionnaires to a Malaysian context is not appropriate or practical.

With that, our aim is to develop a new questionnaire that will be used to assess the KAP regarding IYCF among childcare providers in the northeast part of Peninsular Malaysia. Proper development and validation will result in a well validated, culturally sensitive questionnaire designed specifically for our local childcare providers.

\section{MATERIAL AND METHODS}

\section{Questionnaire development}

The new questionnaire was developed in Kota Bharu, Kelantan from November 2016 to April 2017. This questionnaire was developed in the Malay language, structured and designed specifically to assess childcare providers' KAP regarding IYCF. The questionnaire was developed using a modified Delphi technique; which was then evaluated through cognitive debriefing and pretesting. The questionnaire did not require any translation since it was developed in the native Malay language.

The development of the questionnaire started with the conceptualisation process. This phase was followed by item generation and decisions about the variables involved (independent and dependent variables), that were made through discussions with experts. Four experts participated in the development phase as members of the research team, which included two public health physicians, an infant 
feeding consultant, and a biostatistician. A member of the research team was the coordinator for all communication processes involved (Giesen et al., 2012). Each item or question was discussed in detail to ensure that all respondents could understand it the same way. Vague contents, difficult or ambiguous terms, negative phrases, multiple ideas or concepts in one item, and leading or double-barrelled questions were avoided.

The Delphi technique is a structured group communication process that involves four phases: 1. Exploration of a subject by a group, 2 . Reaching an understanding of how the group views the subject, 3 . Resolving disagreements, and 4. Final evaluation (Linstone, Turoff \& Helmer, 2002). However, a modified Delphi approach was implemented in this study because it allowed the research team members to interact in the final round to clarify issues and present arguments justifying their viewpoints (Eubank et al., 2016). The development process consisted of five phases, namely: 1. Identification of domains, 2. Verification of identified domains, 3. Identification of relevant and representative items, 4. Definition of the domains, and 5. Final verification of the domains and items.

\section{Identification of domains in IYCF}

An extensive literature review on IYCF was conducted. Specifically, this systematic review focused on literature contents that were relevant for the development of the questionnaire, namely on breastfeeding and complementary feeding, the role of childcare providers, assessments of $\mathrm{KAP}$, existing questionnaires, childcare services, and IYCF-friendly centres. Keywords used in database searches were "infant and young child feeding," "childcare providers," "breastfeeding," "complementary feeding," "KAP," and "childcare centres." The databases used included the Cochrane Library,
PubMed, Medline (Web science), Scopus, and Medline Ovid. Each member of the research team comprehensively reviewed a number of questionnaires, which differed widely in their domains, theoretical backgrounds, validation approaches, and the quality of the validation evidence. The research team (experts) also reviewed various locally and internationally published guidelines on IYCF and training guidelines for childcare providers. Relevant literature reviews on other quantitative and qualitative studies, as well as theoretical frameworks were used to incorporate more ideas into the development of the new questionnaire.

The following list of guidelines and references were used during questionnaire development:

1. Modul Latihan Pemakanan Bayi dan Kanak-Kanak [Infant and Young Child Feeding Training Module] (MOH Malaysia, 2008)

2. Modul Kursus Asuhan dan Didikan Awal Kanak-Kanak Permata Negara [PERMATA Basic Child Care Module] (Aminah et al., 2013)

3. Panduan Pengendalian dan Pemberian Susu Yang Selamat di Pusat Jagaan dan Taska [Guidelines on the Safety and Proper Handling of Infant Feeding in Childcare Centers] (MOH Malaysia, 2012),

4. Malaysian Dietary Guidelines for Children and Adolescents $(\mathrm{MOH}$ Malaysia, 2013),

5. WHO Guidelines on Infant and Young Child Feeding (WHO, 2001; WHO, 2003; WHO, 2005), and

6. Published articles (Clark et al., 2008; Freedman \& Alvarez, 2010; Ismail \& Sulaiman, 2010; Lucas et al., 2013; Asis et al., 2016)

All members of the research team suggested possible domains based on their own experiences and review of the literature. Each suggested domain 
was continuously appraised until all members agreed on the number of identified domains to focus on.

\section{Verification of identified domains}

A meeting was then held with the experts to verify the identified domains. To verify the domains, each domain was scrutinised for its appropriateness and applicability to childcare providers. Only domains related to IYCF that were verified by the experts as appropriate for and applicable to childcare providers were included.

\section{Identification of relevant and representative items}

Once the provisional definitions were clear enough to warrant item construction, an email was sent to the research team members (experts) asking them to contribute relevant and representative items for each domain. They were encouraged to contribute as many items as possible, including positively and negatively worded items. These contributed items were then discussed in meetings.

\section{Definition of the domains}

Definitions for the verified domains were agreed on by the research team members. They continuously improved the definitions and critically appraised alternative definitions based on literature reviews and expert opinions, while keeping all definitions within the context of assessing childcare providers' KAP on IYCF. Discussions were continued via e-mail and face-to-face meetings until all research team members (experts) agreed on the provisional definitions for each of the domains.

\section{Final verification of domains and items}

A final meeting was held with all the original research team members (experts) and one additional expert who was not involved in the earlier four initial phases. The domains, definitions, and items were again appraised by the new expert. Response options to these items were also chosen in this meeting, and the advantages and disadvantages of different response formats were considered. The content-validated questionnaire (Draft 1), which has appropriate and relevant content to its construction, was produced during this phase.

\section{Formatting and layout of the new} questionnaire

Draft 1 of the questionnaire was then formatted by researchers to make it more presentable to the respondents for self-administration. For a selfadministered questionnaire, formatting is an essential factor in respondents' motivation in taking time to complete the questionnaire. As a secondary benefit, careful formatting can reduce errors in the subsequent preparation and processing of data. Certain formatting conventions for text, response categories, and overall layout have been shown to enhance data quality and, as a result, are commonly used in questionnaire design (McDonald et al., 2003).

After content validation, the next step was a pre-survey evaluation to assess the response process. This was done through cognitive debriefing (intensive interviews), after which the questionnaire was pre-tested.

\section{Cognitive debriefing}

Cognitive debriefing is part of the response process. It is conducted by researchers to ensure that respondents understood a newly developed questionnaire (Farnik \& Pierzchala, 2012). It functions as a qualitative assessment of the questionnaire. It assesses for any errors that may be introduced by interpretations of specific questions, inability to recall necessary information, or respondents' judgments that might 
affect their answers. In this stage, items that may have been conceptually inappropriate were highlighted. The steps involved in cognitive debriefing, according to (Campanelli, 1997), are:

1. A comprehensive review of each item's intention and the meaning of terms,

2. Retrieval of relevant information and the respondent's view of input,

3. An assessment of the respondent's decision process and whether the respondent devoted sufficient mental effort to answering the questions accurately or were merely guessing,

4. An assessment of the respondent's process to determine whether the response options are clear and whether the respondent's desired options are included, and

5. General comments (e.g. the length of the questionnaire).

The other aim of cognitive debriefing was to identify difficult or confusing items. It was also used to assess whether the questionnaire could be improved. The research team also determined whether some respondents interpreted certain items differently. Alternative suggestions from respondents were recorded, and the questionnaire was amended accordingly. The cognitive debriefing was conducted using the think-aloud method and verbal probing techniques (McDonald et al., 2003; Willis, 2005).

It is recommended that cognitive debriefing be conducted with at least ten participants, including experts and target respondents (Sousa \& Rojjanasrirat, 2011). In this study, cognitive debriefings were conducted with eight childcare providers from one registered childcare centre in the Kota Bharu district, one nutritionist from the Kelantan Health State Department, and one representative from a nongovernmental organisation (NGO) who works with childcare providers and childcare centres (PERASKO).

The results of the cognitive debriefings were reviewed so the findings from this process could be incorporated in the questionnaire. Respondents' interpretations of items were compared to the original version to identify and amend discrepancies. The results of the cognitive debriefing were discussed with the members of the research team. The members evaluated all the respondents' comments and suggestions, and the questionnaire was revised accordingly to produce Draft 2 of the questionnaire.

\section{Pre-testing the questionnaire}

Pre-testing is an assessment of the entire questionnaire, all procedures involved in its administration, and the preparation of its data for analysis. Pretesting was conducted by researchers on a homogenous group of 30 respondents (McDonald et al., 2003). The 30 pre-test participants were childcare providers from nine registered childcare centres in another district.

Draft 2 of the questionnaire (Table 1) was tested to determine the questionnaire's length, user-friendliness and overall flow (including transitions between sections), the level of respondent interest and attention, comprehension of the items, as well as the maximum time needed to respond to the questionnaire. In this study, all respondents answered all the questions within 45 minutes. The overall comments and level of respondent acceptance were good, and the testers provided positive feedback.

The pre-test results (Table 2) were reviewed and finalised to incorporate the findings of the pre-testing process into additional revisions of the questionnaire. Discrepancies in respondents' interpretations of items were identified. The results of the pre-test were explained and discussed with the members of the research team. The members evaluated all the respondents' comments and 


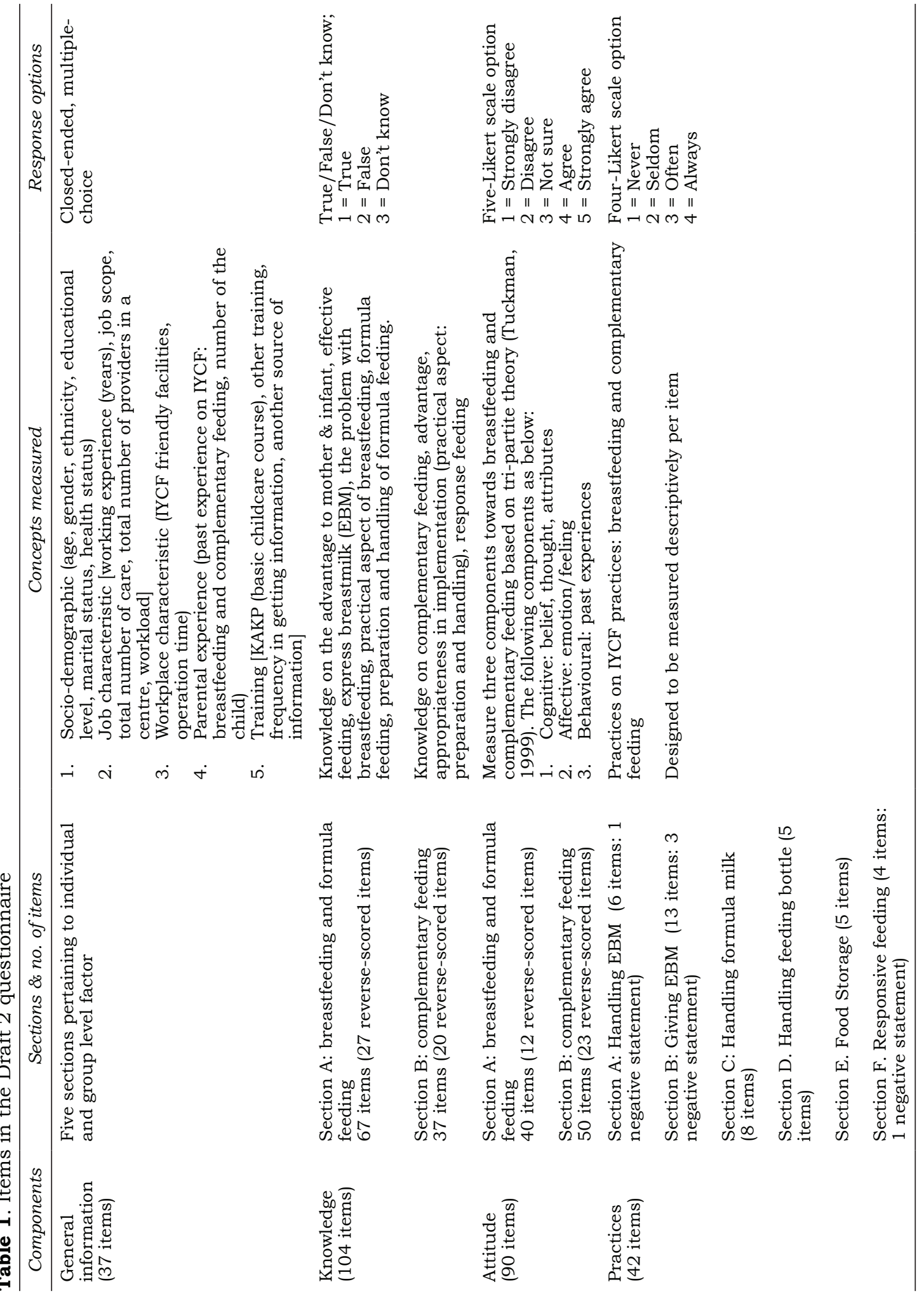


Table 2. Percentage of comment per item for draft 2 of the new questionnaire $(n=30)$

\begin{tabular}{|c|c|c|}
\hline Comment & Mean (SD) & $n(\%)$ \\
\hline \multicolumn{3}{|l|}{$\begin{array}{l}\text { The arrangement of sentences and meaning of the } \\
\text { words }\end{array}$} \\
\hline Well understood & & $24(80.0)$ \\
\hline Difficult to understand certain sentences & & $5(16.7)$ \\
\hline Took some time to understand & & $1(3.3)$ \\
\hline \multicolumn{3}{|l|}{ Type of writing and font size } \\
\hline Met the formatting & & $24(80.0)$ \\
\hline Easy to understand & & $3(10.0)$ \\
\hline Need to increase the font size & & $3(10.0)$ \\
\hline \multicolumn{3}{|l|}{ The arrangement of table and paragraph } \\
\hline Well arranged & & $26(86.7)$ \\
\hline Neat and nice & & $4(13.3)$ \\
\hline \multicolumn{3}{|l|}{ Another comment } \\
\hline Any suggestion & & $2(6.7)$ \\
\hline No suggestion & & $28(93.3)$ \\
\hline Requirement time to answer questionnaire (minutes) & 45.5 (10.45) & \\
\hline
\end{tabular}

\section{Questionnaire development flow chart}

\section{Development of a new questionnaire}

Content expert $(n=4)$

Experts who were a part of the research team were public health physicians, infant feeding consultant, and biostatistician

(Draft 1 of the questionnaire)

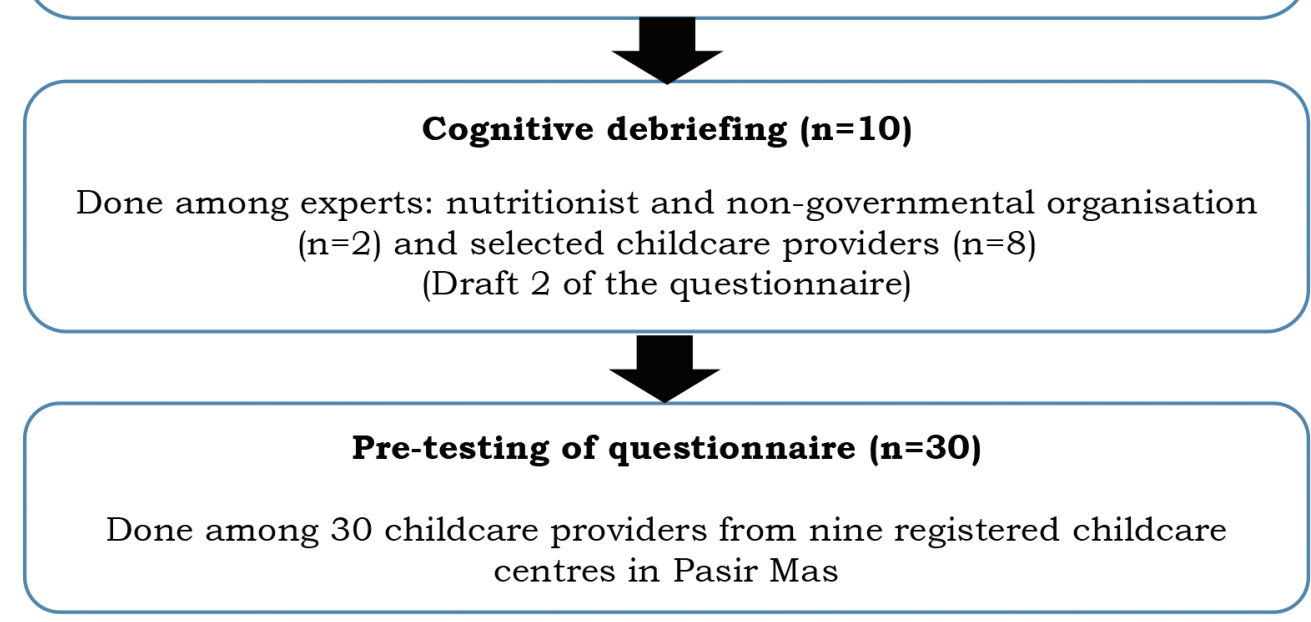

Figure 1. Flow chart on the development, cognitive debriefing and pre-testing of questionnaire 
suggestions, and the questionnaire was revised accordingly to produce Draft 3.

\section{RESULTS}

Four experts were involved in the development phase, and ten respondents participated in cognitive debriefing. Pre-testing was conducted among 30 childcare providers from nine registered childcare centres in Pasir Mas, Kelantan. Most of the childcare providers who participated were young with a mean age of $27 \pm 9.89$ years old, female $(100.0 \%)$, Malay (100.0\%), single (56.7\%), healthy $(93.3 \%)$, and had completed secondary education (86.7\%). Most of them did not have children (56.7\%), so they lacked personal experience with breastfeeding (Table 3).

Table 3. Sociodemographic characteristic of child care providers in Pasir Mas $(n=30)$

\begin{tabular}{|c|c|c|}
\hline Variables & Mean (SD) & $n(\%)$ \\
\hline Age (year) & $27(9.89)$ & \\
\hline \multicolumn{3}{|l|}{ Gender } \\
\hline Female & & $30(100.0)$ \\
\hline \multicolumn{3}{|l|}{ Ethnicity } \\
\hline Malay & & $30(100.0)$ \\
\hline \multicolumn{3}{|l|}{ Education level } \\
\hline Lower than Diploma & & $26(86.7)$ \\
\hline Diploma or higher & & $4(13.3)$ \\
\hline \multicolumn{3}{|l|}{ Marital status } \\
\hline Married & & $13(43.3)$ \\
\hline Single & & $17(56.7)$ \\
\hline \multicolumn{3}{|l|}{ Health status } \\
\hline No comorbidity & & $28(93.3)$ \\
\hline Had comorbidity & & $2(6.7)$ \\
\hline \multicolumn{3}{|l|}{ Employment } \\
\hline Total working experience (years) & $2.2(4.00)^{\ddagger}$ & \\
\hline Experience in the current centre (years) & $2.1(4.40)^{\ddagger}$ & \\
\hline Total working hours per day & $9.2(1.52)$ & \\
\hline \multicolumn{3}{|l|}{ Workload } \\
\hline Total children in centre & $18.0(9.39)$ & \\
\hline Total children cared per provider & $9.0(8.84)$ & \\
\hline Total provider per centre & $3.9(1.56)$ & \\
\hline \multicolumn{3}{|l|}{ Employment scope ${ }^{\dagger}$} \\
\hline Care of child $<2$ years old & & $23(76.7)$ \\
\hline Care of child $>2$ years old & & 25 (83.3) \\
\hline Serve food & & $23(76.7)$ \\
\hline Monitor child during eating & & $21(70.0)$ \\
\hline Other scopes & & $4(13.3)$ \\
\hline Duration of centre operation per day (hours) & $10.8(0.66)$ & \\
\hline Centre having overtime service & & $19(63.3)$ \\
\hline Involvement with overtime service & & $14(46.7)$ \\
\hline \multicolumn{3}{|l|}{ Self-experience } \\
\hline Had own-child & & $8(26.7)$ \\
\hline Total children $(n=8)$ & $0.7(1.37)$ & \\
\hline Breastfeeding experience & & $9(30.0)$ \\
\hline Maximum breastfeeding duration $(n=9)$ & $5.3(10.57)$ & \\
\hline Exclusive breast feeding (yes) & & $1(3.3)$ \\
\hline Age of starting complementary food $(n=8)$ (month) & $1.5(2.58)$ & \\
\hline
\end{tabular}


Table 3. Sociodemographic characteristic of child care providers in Pasir Mas $(n=30)$ (continued)

\begin{tabular}{|c|c|c|}
\hline Variables & Mean (SD) & $n(\%)$ \\
\hline \multicolumn{3}{|l|}{ Facilities at childcare centres $^{\dagger}$} \\
\hline Consent for mother nursing their infant & & $22(73.3)$ \\
\hline Breastfeeding corner & & $16(53.3)$ \\
\hline Refrigerator for EBM & & 28 (93.3) \\
\hline Breast pump & & $1(3.3)$ \\
\hline Educational material & & $22(73.3)$ \\
\hline \multicolumn{3}{|l|}{ Training } \\
\hline KAKP course (involvement) & & $20(66.7)$ \\
\hline Last training (years) $(n=20)$ & $2.2(2.38)$ & \\
\hline Other relevant course & & $18(60.0)$ \\
\hline \multicolumn{3}{|l|}{ Information system } \\
\hline Own initiative to search for information & & 19 (63.3) \\
\hline The frequency of searching information (per month) & $1.4(1.74)$ & \\
\hline \multicolumn{3}{|l|}{ Information system } \\
\hline \multicolumn{3}{|l|}{ Source $^{\dagger}$} \\
\hline Internet & & $16(53.3)$ \\
\hline Books & & $11(36.7)$ \\
\hline Pamphlet & & $10(33.3)$ \\
\hline Magazines & & $12(40.0)$ \\
\hline Support group & & $2(6.7)$ \\
\hline Health care provider & & $8(26.7)$ \\
\hline NGOs & & $0(0.0)$ \\
\hline Others & & $0(0.0)$ \\
\hline \multicolumn{3}{|l|}{ Information source category } \\
\hline No source & & $11(36.7)$ \\
\hline At least one source information & & $5(16.7)$ \\
\hline More than one source information & & $14(46.7)$ \\
\hline
\end{tabular}

${ }^{\dagger}$ Respondents may answer more than one options ${ }^{\ddagger}$ Median (IQR)

During the development process, a total of 233 items were generated for the questionnaire. It consisted of two main components: component A (pro forma, general information) and component $\mathrm{B}$ (addressing the three major domains on knowledge, attitudes and practices regarding IYCF). The two sections (A and B) addressed knowledge and attitude: section A covered breastfeeding and formula feeding, and section $B$ addressed complementary feeding.

The section on knowledge of breastfeeding and formula feeding covered the advantages of breastfeeding to mothers and infants, the effective implementation of breastfeeding, breastmilk expression, breastfeeding problems, and practical aspects of breastfeeding, formula feeding, and the preparation and handling of formula. The section on knowledge of complementary feeding addressed the advantages of complementary feeding, implementation of complementary feeding (including preparation and handling), and the concept of responsive feeding.

The items on attitude were based on the tripartite theory of attitude (Lawrence, 2008). According to this theory, attitude includes cognitive, affective, and behavioural components. The practice domain included six activities: handling expressed breastmilk, feeding 
expressed breastmilk, handling formula, handling bottles, food storage, and responsive feeding. These sections assessed respondents' knowledge on the practical handling of breastfeeding and complementary feeding.

All the domains were defined in the context of IYCF and childcare provider settings. Appropriate Likert scales were designed for the response options in each section (Table 1). Items in the knowledge section had response options of "true," "false," and "don't know." Reverse scoring was used for negatively worded items. One point was given for a correct answer and zero points for an incorrect answer or a response of "don't know." The possible score for this section ranged from 0 to 67 for section A, and 0 to 37 for section B. Each participant's total knowledge score was calculated and then converted to a percentage score by dividing it with the maximum score and multiplying the result by 100 . A higher percentage score on knowledge indicated more knowledge of the item tested.

The items on attitude had response choices of a five-point Likert scale from 1 (strongly disagree) to 5 (strongly agree). Points were assigned in ascending order as follows: 1 = strongly disagree, $2=$ disagree, 3 = unsure, 4 = agree, and 5 = strongly agree. Even-numbered items were positive statements and for these, the Likert scale number was also the item's contribution to the score. For odd-numbered items (the negative statements), the score contribution was 6 minus the Likert score. The score could range from 40 to 200 for section A, and 50 to 250 for section $B$. The practice section consisted of 42 questions rated on a four-point Likert scale. Points were given in ascending order as follows: $1=$ never, 2 = seldom, 3 = sometimes, and $4=$ always. Each item in the practice domain of the questionnaire was described individually.
During cognitive debriefing, six new items were added to the questionnaire and three items were dropped. Several items were rephrased or revised. As a result, a total of 236 items in Draft 2 of the questionnaire were retained for pre-testing. In pre-testing, the overall comments and acceptance of the questionnaire were good, although participants needed a lot of time to answer all the questions. The mean (standard deviation, $S D$ ) time required for respondents to complete the questionnaire was 45(10.45) minutes. Other findings are summarised in Table 2. The questionnaire was revised again based on the results of the pre-testing phase, and 236 items (knowledge: 104 items; attitude: 90 items; practice: 42 items) remained, as in Draft 2 of the questionnaire, for the assessment of internal structural validity as items met the criteria for clarity (Table 1).

The resulting new questionnaire was named the IYCF-CCPQ, which stands for Infant and Young Child Feeding Questionnaire for Childcare Provider or 'Borang Kaji Selidik Pemakanan Bayi dan Kanak-kanak dalam kalangan Pengasuh'. This new questionnaire can potentially be used to assess respondents who are related to the nature of childcare, such as childcare providers, care givers, and parents especially mothers.

\section{DISCUSSION}

The aim of this study was to develop a new questionnaire on IYCF to assess the KAP of childcare providers in registered childcare centres in Kelantan. A modified Delphi technique was used to develop a new questionnaire, the IYCF-CCPQ, which is culturally appropriate for use in Malaysia, especially among the Malay ethnic group.

The questionnaire met the predefined goals. Firstly, the questionnaire was developed specifically for childcare 
providers, which was reflected in its specific content to the context of work among childcare providers. Secondly, Likert scales were used for the responses to simplify the questionnaire's administration and make it suitable for factor analyses. Likert scales have also been used in other studies (Freedman \& Alvarez, 2010; Abdul Ghani et al., 2016; Zahiruddin et al., 2018). Thirdly, the questionnaire was based on the application of the tripartite theory of attitude to IYCF (Pickens, 2005; Lawrence, 2008).

Particular attention was paid to the adequacy of the questionnaire's content, specifically in terms of the number and scope of individual statements and whether they were representative, consistent, and relevant to the context. These issues were considered throughout the development process by the research team members who acted as experts (McDonald et al., 2003; Giesen et al., 2012). In this study, public health physicians, an infant feeding consultant, and a biostatistician brought their expertise to review the concept and content of the designated tool. The item scoring methods were also reviewed by experts, such as the biostatistician. According to Rattray and Jones (2007), content validity can be measured by expert opinions on whether the items and scales represent the domains or concepts that the tool is intended to assess.

Face validity can also provide a superficial understanding of how target respondents might understand and respond to the questions (McDonald et al., 2003). Respondent feedback in cognitive debriefing and pre-testing helped improve the comprehensibility, layout and presentation, as well as the estimated time needed to administer the IYCF-CCPQ. The readability and ambiguity of structures, passages, sentences, answer options, and instructions were also assessed. Readability is particularly important in a self-administered questionnaire and ensures that the questionnaire can be understood by most of the target population, which will increase its response rate. The readability of the IYCF-CCPQ was observed during cognitive debriefing and pre-testing, during which respondents were asked about the readability of the pre-validated IYCF-CCPQ. All respondents stated that they were able to fully understand the pre-final IYCF-CCPQ.

Cognitive debriefing and pre-testing were also among the methods used to determine the IYCF-CCPQ's operational equivalence. In this study, operational equivalence referred to the use of a similar layout, instructions, mode of administration, and measurement method to those of another questionnaire. The IYCF-CCPQ was administered in a similar way to other questionnaires from previous studies (Freedman \& Alvarez, 2010; Lucas et al., 2013; Che' Muda et al., 2018). Self-administration has several advantages: it uses fewer resources than interviews, and is easy and convenient for respondents.

During pre-testing, the overall comments were good, although it took participants some time to answer all the questions. All respondents were motivated to complete the questionnaire. A possible explanation for this might be the questionnaire's standardised format and clear layout, its easily understandable content, and the fact that it was a newly developed comprehensive questionnaire on IYCF. These factors meant that participants were willing to answer all the questions even though it took them 45 minutes. The respondents' answers were symmetrical, and all of the response options were used. This indicated that the choice of responses effectively measured the childcare providers' KAP regarding IYCF. 
We were able to produce a good and comprehensive questionnaire that covered the whole aspect of IYCF, focusing on childcare providers. However, our limitation was the length of the questionnaire. We strongly recommend for future researchers to use this comprehensive and long version of IYCF-CCPQ as a baseline tool to develop a shorter and more brief version of IYCFCCPQ, by separating the sub-sections of breastfeeding and complementary feeding as deemed necessary. With the short and brief version of IYCF-CCPQ, it will help researchers to do comparable studies to assess the validity of these tools. The online version of IYCF-CPQ can also be developed in order to conduct a massive survey regarding infant feeding practices among childcare providers at the national level.

\section{CONCLUSION}

The IYCF-CCPQ is a new questionnaire designed to measure childcare providers' KAP regarding IYCF. In its present form, the questionnaire addresses three domains - knowledge, attitudes and practices, and contains 236 items rated on a Likert scale. Before the IYCFCCPQ is used, a proper validation study should be conducted to determine its psychometric properties.

\section{Acknowledgement}

The authors acknowledge the Universiti Sains Malaysia Bridging Grant (304.PPSP.6316161) for funding this study. Sincere appreciation also goes to the Human Research Ethics Committee Universiti Sains Malaysia (USM) for ethical approval (Reference code: USM/ JEPeM/16100405), Social Welfare Department Putrajaya for granting permission to conduct this study (JKMM 100/12/5/2:2017/061), as well as State and District Welfare Officer, NGOs related to childcare provider (PERASKO \& PTSK), childcare centre administrators, and childcare providers for their participation in this study.

\section{Authors' contributions}

NMZ, principal investigator, conceptualised and designed the study, prepared the draft of the manuscript and reviewed the manuscript, led the data collection in the Northern east region, conducted the study, data analysis and interpretation; TATI, advised on the design and conduct of the study, and reviewed the manuscript; WNAWM, advised on the data analysis and interpretation and reviewed the manuscript; ZS, reviewed the manuscript; TFTH, advised on data collection and reviewed the manuscript.

\section{Conflict of interest}

The authors declare that they have no conflicts of interest regarding this study.

\section{References}

Abdul Ghani MN, Tuan Kamauzaman TH, Mohd Fudzi MFM, Arifin WN \& Chew KS (2016). Development and psychometric evaluation of flood disaster management questionnaire (FloodDMQ-BM): exploratory factor analysis and item response theory analysis. Int $J$ Public Health Clin Sci 3(3):59-70.

Aminah A, Rohani A, Nani M \& Jameyah S (eds) (2013). Modul Pendidik/Pengasuh: Kursus Asuhan dan Didikan Awal Kanak-kanak Permata Negara. Penerbit Universiti Putra Malaysia, Serdang.

Asis SHH, Al-Sadat N \& Abdul Majid H (2016). Role of baby caretakers to sustain breastfeeding among working mothers. Arts Social Sci J 7:1.

Campanelli P (1997). Testing survey questions: new directions in cognitive interviewing. Bulletin of Sociological Methodology/Bulletin de Methodologie Sociologique 55(1):5-17.

Capizzano J \& Adams G (2000). The number of child care arrangements used by children under five: variation across states. National Survey of America's Families. The Urban Institute. Series B, No. B-12.

Che' Muda CM, Ismail TAT, Jalil RA, Hairon SM, Sulaiman Z \& Johar N (2018). Maternal factors associated with the initiation of exclusive breastfeeding among mothers at one week after delivery in two selected hospitals in Kelantan, Malaysia. Malays J Med Sci 25(4):112-121.

Chilton M \& Rose D (2009). A rights-based approach to food insecurity in the United States. Am J Public Health 99(7): 1203-1211. 
Clark A, Anderson J, Adams E \& Baker S (2008). Assessing the knowledge, attitudes, behaviours and training needs related to infant feeding, specifically breastfeeding of child care providers. Matern Child Health J 12:128-135.

DOSM (2014). In: Labour Force Survey Report 2014. Department of statistic Malaysia. From: https://www.statistics.gov.my/dosm [Retrieved September 12 2018].

Eubank BH, Mohtadi NG, Lafave MR, Wiley JP, Bois AJ, Boorman RS \& Sheps DM (2016). Using the modified Delphi method to establish clinical consensus for the diagnosis and treatment of patients with rotator cuff pathology. BMC Med Res Methodol 16(1):56.

Farnik M \& Pierzchala W (2012). Instrument development and evaluation for patient-related outcomes assessments. Patient Relat Outcome Meas 3:1-7.

Freedman MR \& Alvarez KP (2010). Early childhood feeding: assessing knowledge, attitude, and practices of multi-ethnic child-care providers. $J$ Am Diet Assoc 110:447-451.

Giesen D, Meertens V, Vis-Vischeers R \& Beukenhorst D (2012). Questionnaire development. Statistics Netherlands. From: http: / /www.cbs.nl/NR/rdonlyres /99B7482FE09E-4D8690A 1666DC42745BD / 0/ 2012 Questionairedevelopmentart.pdf. [Retrieved October 28 2016].

Ismail TAT \& Sulaiman Z (2010). Reliability and validity of a Malay-version questionnaire assessing knowledge of breastfeeding. Malays $J$ Med Sci 17(3):32-39.

Lawrence NK (2008). Attitudes and attitude change. In: SF Davis \& W Buskist (eds). 21st century psychology: a reference handbook, Vol. 2 (pp. 104-113). Sage Publication, California.

Linstone H, Turoff M \& Helmer O (2002). The delphi method: techniques and applications. AddisonWesley Publishing Company, California.

Lucas A, McMahon PM, Asling MB, Knobloch A, Kosh E \& Sims K (2013). Assessing child care providers' knowledge and attitudes regarding support of breastfeeding in a region with low breastfeeding prevalence. J Hum Lact 29(4): 556-563.

McDonald JA, Nancy B, Victor GC \& Renee LJ (2003). Questionnaire design. Reproductive Health Epidemiology Series, Module 4. Centers for Disease Control and Prevention, Atlanta, Georgia.

MOH Malaysia (2008). Garis panduan pemberian makanan bayi dan kanak-kanak kecil (pp. 1-5). Bahagian Pemakanan Kementerian Kesihatan Malaysia, Putrajaya.
MOH Malaysia (2012). Panduan pengendalian dan pemberian susu yang selamat di pusat jagaan dan taska (pp. 1-22). Bahagian Pemakanan Kementerian Kesihatan Malaysia, Putrajaya.

MOH Malaysia (2013). Malaysian dietary guidelines for children and adolescents (pp. 2225). National Coordinating Committee on Food and Nutrition, Ministry of Health Malaysia, Putrajaya.

National Population and Family Development Board (2014). In: Malaysian Population and Family Survey 2014. From: http://www.lppkn. gov.my. [Retrieved September 28 2018].

Quisumbing AR, Brown LR, Feldstein HS, Haddad L \& Pena C (1995). Women: the key to food security. Food Policy ReportA. The International Food Policy Research Institute, Washington.

Pickens J (2005). Attitudes and perceptions. Organizational Behavior in Health Care (pp. 43-76). Jones and Bartlett Publisher, Massachusetts.

Rattray J \& Jones MC (2007). Essential elements of questionnaire design and development. $J$ Clin Nurs 16(2): 234-243.

Sousa VD \& Rojjanasrirat W (2011). Translation, adaptation and validation of instruments or scales for use in cross-cultural health care research: a clear and user-friendly guideline. $J$ Eval Clin Pract 17(2): 268-274.

WHO (2001). Guiding principles for complementary feeding of breastfed child (pp. 5-37). Division of Health Promotion and Protection Food and Nutrition Program, World Health Organization, Geneva.

WHO (2003). Global strategy for infant and young child feeding ( $p$. 1-30). World Health Organization, Geneva.

WHO (2005). Guiding principles for complementary feeding of non-breastfed child (pp. 3-40). Division of Health Promotion and Protection Food and Nutrition Program, WHO, Geneva.

Willis GB (2005). Cognitive interviewing: a tool for improving questionnaire design (pp. 42-52). Sage Publication, London.

Zahiruddin WM, Arifin WN, Mohd Nazri S, Sukeri S, Zawaha I, Bakar RA, Hamat RA, Malina O, Jamaludin TZMT \& Pathman A (2018). Development and validation of a new knowledge, attitude, belief and practice questionnaire on leptospirosis in Malaysia. BMC Public Health 18(1): 331. 